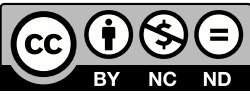

Estudos Teológicos foi licenciado com uma Licença Creative Commons Atribuição - NãoComercial - SemDerivados 3.0 Não Adaptada

http://dx.doi.org/10.22351/etv59i2.3548

\title{
Moltmann E O diÁLOGo INTER-REligioso ${ }^{1}$
}

Moltmann and the inter-religious dialogue

Fabrício Veliq ${ }^{2}$

Resumo: Este artigo mostra, em linhas gerais, a inserção do teólogo alemão Jürgen Moltmann no contexto do diálogo inter-religioso em seu percurso teológico. No intuito de mostrar isso, partimos do fato de que Moltmann considera o diálogo como parte da missão da igreja e o cristianismo como catalisador crítico no contato com as outras religiões. Em seguida, mostramos que Moltmann não assume uma postura relativista ou pluralista dentro da questão do diálogo inter-religioso e terminamos mostrando a diferenciação que faz entre o diálogo inter-religioso direto e indireto, com uma pequena indicação sobre o que Moltmann considera importante no que tange ao discernimento dos espíritos.

Palavras-chave: Diálogo inter-religioso. Jürgen Moltmann. Relação.

Abstract: This article aims to show in general lines Jürgen Moltmann's insertion into the inter-religious dialogue context through his theological path. To do so, we have shown that Moltmann considers dialogue as part of church mission and the Christianity as critical catalyst in its contact with other religions. After that, we have shown that Moltmann does not put himself as relativist or pluralist theologian in the inter-religious quest. We have finished the article showing the difference that Moltmann establishes between direct and indirect inter-religious dialogue and a small indication about what Moltmann considers important in the discernment of the spirits quest.

Keywords: Inter-religious dialogue. Jürgen Moltmann. Relation.

\section{Introdução}

O teólogo alemão Jürgen Moltmann não esteve alheio, ao longo de sua obra, em relação à importância que há no diálogo com as outras religiões. Em seu pensamento, a ideia do diálogo se torna extremamente importante para a nova situação do mundo em que vivemos, em que se manifestam diversas culturas e religiões. Dessa

1 O artigo foi recebido em 08 de janeiro de 2019 e aprovado em 01 de julho de 2019 com base nas avaliações dos pareceristas ad hoc. Pesquisa financiada pela CAPES. Este artigo é dedicado a Lucília Barbosa e Andréa Ruas Veliq.

2 Doutor. Universidade Federal de Minas Gerais, Belo Horizonte, MG. E-mail: fveliq@gmail.com 
forma, pensar o diálogo inter-religioso como algo sério e, mais ainda, como missão da própria igreja parece ser imprescindível para Moltmann. Neste artigo, queremos mostrar as linhas gerais do pensamento de Moltmann a respeito do diálogo inter-religioso. Mesmo que essa temática não tenha sido uma sobre as quais tenha se debruçado com grande afinco, suas indicações se mostram importantes para se pensar o diálogo inter-religioso, principalmente pneumatológico, em tempos contemporâneos.

\section{O diálogo como missão}

Moltmann insere a questão do diálogo dentro da categoria da missão da igreja que visa a uma transformação qualitativa a respeito da humanidade ${ }^{3}$, o qual chama de "contaminação" das pessoas, seja qual for sua religião, com o espírito da esperança, amor e da responsabilidade pelo mundo. Para nosso teólogo, essa missão qualitativa acontece no diálogo entre as religiões. Para ele, "o diálogo das religiões universais é um processo para o qual podemos nos abrir somente se nos tornamos vulneráveis na abertura e quando saímos dele transformados"4.

Chamamos a atenção para o fato de que, no pensamento de nosso teólogo, esse diálogo não implica uma perda da identidade cristã, antes ganhar mediante esse encontro com o outro um novo perfil que, de acordo com a esperança cristã, são voltados para o bem dos seres humanos, para a vida e para a paz. Nesse sentido, Moltmann propõe que o cristianismo desconstrua os preconceitos em relação a outras religiões. ${ }^{5}$

Esse pensamento também se manifesta em um artigo publicado em 1973, em que Moltmann afirma:

a primeira consequência para a cristandade é que a Igreja só pode apresentar a universalidade da entrega de Deus em Cristo a todos os homens se empreender um diálogo e uma cooperação sem condições com grupos de outras crenças ${ }^{6}$.

A consequência de se pensar a universalidade da salvação trazida por Deus por meio de Cristo, no pensamento de Moltmann, envolve repensar o velho adágio de que "fora da igreja não há salvação" e redizê-lo de outra forma. Moltmann, então, propõe que

fora da salvação que Cristo traz para todos os seres humanos também não há Igreja. A Igreja visível é como Igreja de Cristo o serviço praticado da reconciliação do mundo.

3 Essa ideia pode também ser percebida em MOLTMANN, Jürgen. El Espíritu Santo y la teología de la vida. Isidorianum, Sevilla, v. 7, n. 14, 1998. p. 359-360: "Missio Dei não é nada menos que o envio do Espírito Santo pelo Pai mediante o Filho a este mundo, para que este mundo não se perda, senão que viva".

4 MOLTMANN, Jürgen. Igreja no poder do Espírito. Santo André: Academia Cristã, 2013. p. 204.

5 MOLTMANN, 2013, p. 204.

6 MOLTMANN, Jürgen. Ecumenismo en el servicio al mundo. Selecciones de Teología, Barcelona, v. 12, n. 46, abr./jun.1973. p. 175. 
Nesta perspectiva, a Igreja já não é vista de forma absoluta, mas em sua relação com o reconciliador divino e com o ser humano reconciliado, independentemente da religião ${ }^{7}$

Não estaria aqui se descortinando uma possível abordagem para a questão do discernimento da ação do Espírito nas outras religiões? Será possível pensarmos que ali onde o humano é reconciliado consigo mesmo, com sua comunidade e com a natureza, ali está a ação do Espírito de Cristo, independente da religião a que esse homem ou mulher pertença?

\section{O cristianismo como catalisador crítico}

Moltmann posiciona-se contra toda forma de absolutismos, seja de um absolutismo da própria fé, visto que, no pensamento de nosso teólogo, a própria fé é uma crítica da religião e é também diferente dessa ${ }^{9}$, seja o de um governo absoluto por parte da igreja cristã que se mostrou no Ocidente desde a sua ligação com o poder romano por meio da conversão de Agostinho.

Com isso, nosso teólogo também faz uma crítica ao documento Nostra Aetate, documento elaborado pelo Concílio Vaticano II que trata da posição católica frente às religiões não cristãs, mais especificamente o budismo, hinduísmo, islão e judaísmo, tendo como base aquilo que considera sua função, a saber, "fomentar a união e a caridade entre os homens e até entre os povos" $"$. Para ele, nesse documento o que se apresenta é uma ideia absolutista mais branda e, talvez, mais esclarecida ${ }^{11}$, mas, ainda assim, mostra o cristianismo como uma religião superior às outras e como auge para um relacionamento com Deus, o que dificulta muito a questão de um diálogo verdadeiro com as outras religiões.

Moltmann também considera que essa relação do cristianismo com as outras religiões, tradicionalmente, seguiu uma linha absolutista e monológica, e não uma linha dialógica. Isso, segundo ele, pode ser percebido no modelo de natural e sobrenatural, que mostra que enquanto as outras religiões pertencem à ordem do conhecimento natural a respeito de Deus, o cristianismo é o representante de um mistério que é de ordem sobrenatural. Assim, a ideia de que o cristianismo possui uma verdade mais completa por trás dos elementos de verdade das outras religiões é percebido na própria definição do Vaticano II. ${ }^{12}$

MOLTMANN, 2013, p. 205.

8 Cf. MOLTMANN, 2013, p. 206.

9 Cf. MOLTMANN, Jürgen. Christianity and the World Religions. In: HICK, John; HEBBLETHWAITE, Brian (Eds.). Christianity and Other Religions. Philadelphia: Fortress, 1981. p. 197.

${ }^{10}$ DECLARAÇÃO Nostra Aetate sobre a igreja e as religiões não-cristãs, 1. Disponível em: $<$ http://www. vatican.va/archive/hist_councils/ii_vatican_council/documents/vat-ii_decl_19651028_nostra-aetate_ po.html >. Acesso em: 27 maio 2019.

11 MOLTMANN, 1981, p. 205. Ver também MOLTMANN, 1981, p. 196.

12 Ver MOLTMANN, 1981, p. 201-202. A nosso ver, esse tipo de pensamento também pode ser percebido em linhas mais inclusivistas. Nessas, o cristianismo é responsável por identificar e aperfeiçoar aquilo que há de bom nas outras religiões. 
Dessa forma, Moltmann considera que pensar o cristianismo como catalisador crítico pode ser um novo modelo dentro de uma era pós-absolutista. O catalisador, em química, é aquilo que mediante a sua presença faz com os elementos reajam entre si. Para Moltmann, a presença do cristianismo entre as outras religiões teria o mesmo efeito que um catalisador, ou, como também chama: uma "contaminação indireta" das outras religiões com ideias cristãs, valores e princípios, sempre atento às ambiguidades que pode haver ao se entender cristianismo somente em sua forma ocidental. Nas suas palavras:

Quando o cristianismo em sua relação com outras religiões renuncia à reivindicação da verdade absoluta e também à arrogância de reivindicar integrações, apresenta-se como possível novo modelo para sua era pós-absolutista o modelo de catalisador crítico ${ }^{13}$.

A ideia do cristianismo como catalisador crítico é algo que Moltmann toma de Hans Küng. Isso foi desenvolvido em seu livro Ser Cristão, e pode ser sintetizado no seguinte trecho:

Antes o livre e desinteressado serviço cristão ao homem nas religiões. Exatamente a partir de uma abertura que é mais do que acomodação condescendente; que não renega as próprias conviç̧ões religiosas, como também não impõe nenhuma solução determinada; que transforma a crítica alheia em autocrítica e, simultaneamente, aceita tudo que for positivo; que nada destrói que tiver valor nas religiões, como não assimila criticamente nada que não tem valor. Portanto, o cristianismo deve prestar o seu serviço entre as religiões universais no jogo dialético do reconhecimento e rejeição: qual catalisador crítico e ponto de cristalização dos seus valores religiosos, éticos, meditativos, ascéticos e estéticos. [...] Em poucas palavras: nem absolutismo arrogante que não dê valor a mais nada. Nem ecletismo indolente a fazer valer uma pitada de tudo. Mas um universalismo cristão, inclusivo, a pleitear para o cristianismo não exclusividade, mas singularidade ${ }^{14}$.

Assim como Küng, Moltmann vê a necessidade de estar na relação com as outras religiões em perfil dialogal, sem, contudo, perder a própria identidade. Em suas palavras:

Os cristãos podem falar de sua missão particular somente quando tomam conhecimento e respeitam as missões de caráter diferente de outras religiões. Podem entrar num diálogo razoável com elas somente quando não querem apenas dar algo, mas também receber algo. Pertence a um diálogo frutífero, por um lado, um claro conhecimento acerca da identidade da própria fé, mas por outro lado também um senso para a própria incompletude e uma necessidade verdadeira de comunhão com os outros ${ }^{15}$.

${ }^{13}$ MOLTMANN, 2013, p. 211.

${ }_{14}$ KÜNG, Hans. Ser Cristão. Rio de Janeiro: Imago, 1974. p. 92.

15 MOLTMANN, 2013, p. 212. Essa mesma posição é defendida por Moltmann em MOLTMANN, 1999, p. 248. A nosso ver, nesse ponto se exclui alguma possível acusação de uma postura imperialista no pensamento moltmanniano, uma vez que assume o "senso de incompletude" do cristianismo e postula a necessidade de verdadeira comunhão com as outras religiões mundiais. 
Diante do mundo plural em que vivemos, Moltmann propõe que sejamos tolerantes com as outras religiões, não, contudo, uma tolerância cética, antes uma tolerância produtiva, como proposta por Lessing, em que "cada religião é um meio de educar para a humanidade e uma fase de passagem para a autêntica moralidade"16.

\section{Nem relativista nem pluralista}

Nosso teólogo, porém, não pensa a questão do diálogo inter-religioso por um viés relativista ou pluralista, que é o que se pode esperar ao se falar em tolerância religiosa. Para ele, o relativismo pode simplesmente disfarçar outra forma de absolutismo. ${ }^{17}$ Segundo Moltmann, a verdade do relativismo e da tolerância justificada por ele deve ser procurada provavelmente na relacionalidade.

Uma vida e uma religião tornam-se relativas ao se comportarem de maneira relacional, assumindo relações vivas com outra vida e outras religiões. Em relações vivas não se torna "tudo" de valor igual e com isto indiferente, mas uma coisa se torna para a outra extremamente significativa. ${ }^{18}$

Com relação ao pluralismo religioso, Moltmann, em um capítulo escrito em 1990, pondera a necessidade de distinguir entre um pluralismo que encoraja a liberdade religiosa individual como reconhecimento formal dos direitos humanos e o pluralismo empírico que acontece entre as religiões da Ásia e da África. ${ }^{19}$

Nesses continentes, segundo nosso teólogo, tem surgido um cristianismo que não pretende absolutismos como consequência da doutrina cristã, antes se percebe um convívio não violento com as outras religiões que vivem no mesmo espaço.

Nas palavras de Moltmann:

O pluralismo, nesses casos, não é uma teoria geral meta-religiosa de interrelação entre as tradições religiosas, mas a aceitação autoevidente da realidade das outras comunidades religiosas, a aceitação de conviver com elas, realizando a tarefa da comunidade cristã com métodos adaptados às circunstâncias ${ }^{20}$.

No Ocidente, a história se mostra diferente. Para nosso teólogo, desde a Idade Moderna o que aconteceu foi um deslocamento para a crença subjetiva e, assim, a liberdade religiosa passou a significar a liberdade de adorar na igreja que você escolher,

${ }^{16}$ MOLTMANN, 2013, p. 209.

17 MOLTMANN, 2013, p. 209. Em MOLTMANN, 1981, p. 200, Moltmann chegará a definir absolutismo e relativismo como gêmeos: "Absolutismo e relativismo são realmente gêmeos, porque ambos veem tudo a partir de uma torre de vigia alta, não-histórica".

${ }^{18}$ MOLTMANN, 2013, p. 210.

19 MOLTMANN, Jürgen. Is "Pluralistic Theology" Useful for the Dialogue of World Religions? In: D'COSTA, Gavin (Ed.). Christian Uniqueness Reconsidered: the Myth of a Pluralistic Theology of Religions. New York: Orbis, 1990a. p. 151.

${ }^{20}$ MOLTMANN, 1990a, p. 151. 
ou até mesmo não adorar. ${ }^{21}$ Para Moltmann, a religião, assim, perde seu caráter social e vai para o âmbito privado.

Diferentes tradições religiosas perdem suas capacidades de ser o elemento de vínculo das sociedades e se tornam, ao invés disso, meras opções para consumidores religiosos a selecionar, para suas próprias razões privadas, razões não são para serem discutidas. Assim "democratizadas" religiões entram no mercado como objetos de escolhas subjetivas do mesmo modo que marcas de pasta de dente e sabão em pó: "Religião é agora um item de consumo para uma nação de 'estou dando uma olhadinha (Window shoppers)', diz Martin Marty. ${ }^{22}$

Diante disso, Moltmann chama a atenção para o fato de que, em nosso mundo ocidental atual, a ideia de uma religião de consumo se coloca como aquilo que Herbert Marcuse definiu como uma "tolerância repressiva" 23 , uma vez que, segundo Moltmann, "se é tolerante ao se permitir tudo numa perspectiva subjetivista e repressiva no sentido do ceticismo sobre qualquer realidade objetiva sendo mediada pelos símbolos religiosos e que deve ser aceito por todos da mesma forma que se exigia da fé cristã na época do Império de Constantino"24.

Uma vez que isso acontece, nosso teólogo se questiona a respeito da possibilidade de haver um verdadeiro diálogo inter-religioso. Ao se tentar fazer a adequação de todas as religiões e fazer com que elas abram mão de seu discurso a respeito da verdade, em uma espécie de self-service em que pegamos aquilo que nos agrada em cada uma delas em troca de uma possível segurança, tornando todas as religiões igualmente válidas, as pessoas podem considerar essas religiões como indiferentes para sua vida. ${ }^{25}$

Pluralismo então pode tomar a forma de um ceticismo pio no qual pessoas pegam o melhor do que é oferecido, mas o fazem de maneira estupefata; ele também pode assumir uma forma a-religiosa quando pessoas renunciam a todas as escolhas religiosas porque elas descobrem que podem viver igualmente sem elas. ${ }^{26}$

${ }^{21}$ MOLTMANN, 1990a, p. 152. Ver também MOLTMANN, Jürgen. Fundamentalismo e modernidade. Concilium Brasil, Petrópolis, n. 241, maio 1992. p. 144. Essa temática também aparece em MOLTMANN, Jürgen. A Common Earth Religions: World Religions from an Ecological Perspective. Ecumenical Review, Geneva, v. 63, n. 1, p. 16-24, mar. 2011.

22 MOLTMANN, 1990a, p. 152.

${ }^{23}$ Esse tema foi desenvolvido por Hebert Marcuse em WOLFF, Robert Paul; MOORE JR, Barrington; MARCUSE, Herbert. A Critique of Pure Tolerance. Boston: Beacon, 1969. p. 95-137. Para a tradução para o português, recorremos à tradução de OLIVEIRA, Kathlen Luana. Tolerância repressiva. Protestantismo em Revista, São Leopoldo, v. 12, p. 28-58. Nesse texto, o autor desenvolve a ideia de que "a tolerância apresenta-se novamente como o que era em suas origens, no começo do período moderno - uma meta partidária, uma prática e uma noção libertária subversiva. Contrariamente, o que hoje é proclamado e praticado como tolerância está, em muitas de suas manifestações mais efetivas, servindo a causa da opressão" (p. 1-2).

24 MOLTMANN, 1990a, p. 152.

${ }^{25}$ Contudo, seria possível pensar um judaísmo sem a Torá, ou um islamismo sem a Sharia, ou ainda um cristianismo sem o sermão do monte? Traços dessa pergunta reverberam em MOLTMANN, 2011, p. 20:

"uma religião que não exige nada não pode oferecer conforto".

${ }^{26}$ MOLTMANN, 1990a, p. 152. 
Com relação à corrente pluralista a respeito do diálogo inter-religioso que surge com John Hick e é também seguida por Paul Knitter, Moltmann também a considera como imperialista no sentido que tenta definir o fundamento válido para o diálogo entre todas as religiões. Nas palavras de Moltmann:

\begin{abstract}
Uma teologia pluralista das religiões pode não ser menos imperialista que as teologias cristãs das religiões que Knitter quer superar. A natureza verbal do processo de "diálogo", por exemplo, já dá às chamadas "religiões do livro" uma vantagem importante. Uma teoria relativista da religião pode ser necessária para os Estados Unidos, dada sua diversidade. Até onde o pluralismo americano é um modelo situável da relação que deveria haver entre as religiões mundiais deve ser motivo de debate mais do que assumido como verdadeiro $^{27}$.
\end{abstract}

Cerca de 14 anos depois, ainda dirá que “o 'pluralismo' como tal não é uma religião e nem se constitui numa teoria particularmente útil para o diálogo inter-religioso. Quem parte dessa divisa logo nada mais terá a dizer e ademais ninguém lhe dará ouvidos" 28 .

Com isso, Moltmann também levanta a questão se são somente aquelas religiões que cumprem as condições para diálogo propostas pela teologia pluralista são capazes do diálogo.

\title{
A dignidade para o diálogo sério
}

Uma pergunta, então, nos surge: no pensamento de Moltmann, quem são aqueles capazes de dialogar? Para Moltmann, o teólogo ou teóloga que se propõe a dialogar com as outras religiões, além da capacitação para isso por meio do estudo da outra religião, precisa também se tornar digno de participar do diálogo inter-religioso. Essa dignidade, no pensamento de nosso teólogo, tem aquele ou aquela que já alcançou uma posição firme na sua própria religião, e já está domiciliado nela, uma vez que "os representantes de outras religiões não querem conversar com modernos relativizadores da religião, mas com cristãos, judeus, islamitas etc. convictos" 29 .

Isso não quer dizer que somente quem possui um conhecimento formal pode participar do diálogo, mas, para Moltmann, a firmeza naquilo que se crê e a abertura para ouvir são fundamentais para esse tipo de diálogo. O próprio Moltmann chega a afirmar que "como marxista ou como muçulmano, eu teria pouco interesse em um cristianismo que faz concessões vitais antes de entrar em conversa comigo" 30 .

Dessa forma, em um diálogo inter-religioso sério, cada participante tem claro para si aquilo que é próprio de sua própria religião e através do olhar do outro é

${ }^{27}$ MOLTMANN, 1990a, p. 155

${ }^{28}$ MOLTMANN, Jürgen. Experiências de reflexão teológica: caminhos e formas da teologia cristã. São Leopoldo: Unisinos, 2004. p. 29.

${ }^{29}$ MOLTMANN, 2004, p. 29.

${ }^{30}$ MOLTMANN, 1990a, p. 155 
possível chegar a uma visão mais depurada da sua própria religião. No diálogo inter-religioso cada participante é uma testemunha da verdade de sua religião. ${ }^{31}$

Para Moltmann, um diálogo é sério quando se torna necessário e ele é necessário quando há algum conflito que ameaça a vida e uma solução pacífica deve ser buscada a fim de salvaguardá-la. ${ }^{32}$

Diante disso, Moltmann propõe que cada participante de um diálogo inter-religioso deve trazer a si próprio e a verdade de sua religião, sem preocupação de se chegar a um consenso, visto não ser esse o objetivo de um diálogo.

Nas palavras de Moltmann:

Cada parceiro deve trazer para o diálogo a si próprio com toda a verdade de sua religião. A troca de gentilezas não ajuda a ninguém. O diálogo deve girar em torno da pergunta pela verdade, mesmo que não seja possível chegar a um consenso em relação a ela. Pois o consenso não é o objetivo do diálogo. Se um dos parceiros for convencido pelo outro, acaba o diálogo. Quando dois dizem a mesma coisa, um deles está sobrando. Para o diálogo inter-religioso sobre o que "concerne incondicionalmente" às pessoas e no que elas colocam toda a confiança do seu coração, já o caminho é uma parte do alvo, na medida em que ele possibilita convivência em meio às diferenças intransponíveis ${ }^{33}$.

Com base em sua participação no diálogo cristão-marxista na década de 1960, Moltmann pontua aquilo que considera importante para um diálogo sério. Em suas palavras:

No diálogo cristão-marxista e nos eventos que transpiraram depois desses, eu aprendi que devemos tomar os pontos fortes do parceiro seriamente e abster-se das litanias de crítica de seus atalhos e erros. Eu aprendi que um não perde a identidade no diálogo, mas atinge um profundo sentimento daquela identidade. No despertar de um diálogo honesto, não se pode ver a si mesmo em autoimagens romantizadas, mas com os olhos críticos dos outros. Eu finalmente entendi que em diálogo sério não pode haver evasão das questões difíceis por recorrer a uma autoridade superior não aberta à inspeção crítica pelos outros. Adicionalmente, a natureza do diálogo não era nosso tópico; nós discutíamos seriamente cristianismo e marxismo; nós não tínhamos um diálogo sobre diálogo. Somente depois ficou claro para nós que os reais problemas não surgiam entre cristãs e marxistas cabeças abertas, mas de marxistas e cristãos que não eram parte do diálogo ${ }^{34}$.

\section{O diálogo inter-religioso direto e o indireto}

Diante disso, Moltmann distingue dois tipos de diálogo possíveis, a saber, o diálogo direto e o diálogo indireto. O primeiro, para nosso teólogo, envolve as religiões mundiais, que são assim chamadas por não pertencerem a nenhum povo, língua

\footnotetext{
31 MOLTMANN, 2004, p. 29.

32 Essa ideia também se mostra presente na análise que Moltmann faz de sua participação no diálogo com cristãos marxistas na Europa, na década de 1960. Ver MOLTMANN, 1990, p. 154.

33 MOLTMANN, 2004, p. 29.

34 MOLTMANN, 1990a, p. 153
} 
ou cultura específica e estarem presentes em todo o mundo, tais como o cristianismo, budismo, islamismo, dentre outras.

No diálogo direto, segundo nosso teólogo, é que ocorre a confrontação a respeito dos conceitos de salvação, transcendência, antropologias etc., e é nesse diálogo que o cristianismo precisa se fazer representar de forma séria. No entanto, Moltmann tem consciência de que a ideia de que se chegará à paz por meio de diálogos tem um caráter totalmente ocidental, uma vez que as religiões que possuem livros são mais bem preparadas para questões verbais e argumentações do que as religiões mais rituais da África e as meditativas do Oriente, sendo até mesmo notável que as "religiões naturais" da África, Austrália e América não estejam representadas nesse programa de diálogo direto. ${ }^{35}$

O diálogo indireto se dá quando se estão em jogo as questões sociais e as questões ecológicas. Diante dos atuais problemas de nosso mundo hodierno, e no reconhecimento dos problemas que o assolam, tais como a crise ecológica, a ameaça nuclear etc., o intercâmbio entre as religiões se dá visando a caminhos para escapar dessas ameaças. Nesse sentido, não se fala sobre si mesmo ou sobre um nós em relação a um outro, mas, conjuntamente, se fala a respeito de um outro assunto. ${ }^{36}$

Para Moltmann, nesse diálogo indireto é que as religiões primitivas, com seus conhecimentos milenares a respeito da terra e sua sabedora social, começam a se expressar e ser ouvidas, a fim de que possamos lutar para a sobrevivência do mundo. ${ }^{37}$

Diante disso, para Moltmann, no futuro, uma religião será considerada mundial somente se "promover e assegurar a sobrevivência da humanidade no quadro do organismo Terra" ${ }^{38}$. Essa mesma ideia, se observarmos atentamente, já estava presente em sua obra Igreja no poder do Espírito, quando Moltmann afirma que

Como religião universal poderão se apresentar e sobreviver futuramente somente aquelas religiões que se abrem para o "mundo único" que está surgindo e para a "história universal" comum que hoje ainda precisa ser criada. Esta é uma nova situação para as religiões, inclusive o cristianismo ${ }^{39}$.

Dessa forma, para nosso teólogo, é necessário que o diálogo inter-religioso se dirija às pessoas que sofrem no mundo e não fique somente em conversas de alto escalão, que geralmente pouco ajudam os que passam necessidade. Somente assim, o

\footnotetext{
35 MOLTMANN, 2004, p. 30.

${ }^{36}$ MOLTMANN, 2004, p. 30. Ver também MOLTMANN, 1990, p. 155.

37 MOLTMANN, 2004, p. 30.

38 MOLTMANN, 2004, p. 30. Ver também MOLTMANN, 2011, p. 23.

39 MOLTMANN, 2013, p. 202. Ver também MOLTMANN, Jürgen. Direitos humanos, direitos da humanidade e direitos da natureza. Concilium Brasil, Petrópolis, n. 228, mar. 1990b, p. 151: "somente se tornam religiões 'universais' ali onde começam por se integrar nas condições e exigências da vida, e na emergente comunidade de direitos deste mundo único, ao mesmo tempo em que se mostrarem dispostas a abrir mão das suas exigências de Absoluto particular em proveito do universalismo da verdade".
} 
diálogo pode se mostrar como sinal de esperança, ou seja, quando se realiza em seu interesse pela vida e libertação dos que sofrem. ${ }^{40}$

Partindo da premissa de que cultura e religião não se separam, Moltmann defende que, no que tange à indigenização cultural, é necessário que surja um cristianismo japonês, chinês, indonésio, árabe e africano, bem como, por meio do diálogo, que também haja um cristianismo budista, hinduísta, muçulmano, animista, confucionista, xintoísta etc. Tudo isso visando à tarefa cristã de preparação do mundo para o reino de Deus que vem. ${ }^{41}$

Cultura e religião não podem ser separadas. Por isto teremos que perguntar também hoje por motivos hinduístas, budistas e muçulmanos para a fé em Jesus. Isto não pode ser condenado como sincretismo. Um cristianismo colorido por diferentes civilizações não resulta em uma mistura cultural; e um cristianismo tingido com diferentes religiões não produz simplesmente uma mistura religiosa. [...] Se for a vocação particular da cristandade preparar o tempo messiânico entre os povos e preparar o caminho da redenção que vem, então nenhuma cultura pode ser reprimida e nenhuma religião, extinta. Ao contrário, todas podem ser acolhidas e transformadas carismaticamente no poder do Espírito. Com isso são orientadas em direção ao reino. Para o cristianismo, o diálogo com as religiões universais dá-se no ambiente mais amplo da libertação de toda a criação para o Reino que está vindo. ${ }^{42}$

No que tange ao discernimento dos espíritos, tema basilar para se pensar um diálogo inter-religioso, principalmente em viés pneumatológico, o critério proposto por Moltmann é bem simples e direto. Esse critério é a cruz de Cristo. Dessa forma, todo espírito que permanece ao passar pelo crivo da cruz de Cristo e aquilo que é manifestado nela procede de Deus. Caso contrário, esse espírito não procede do Pai e deve ser considerado demoníaco.

Em suas palavras:

Como qualquer leitor pode reconhecer, para mim, o verdadeiro critério para o discernimento espiritual é a cruz e o discipulado (Nachfolge) de Cristo, no qual tomamos nossa cruz. Aquilo que permanece quando é confrontado com o Crucificado é Espírito

${ }^{40}$ Cf. MOLTMANN, 2013, p. 216. Ver também MOLTMANN, 1990b, p. 152: “o diálogo entre as religiões hoje deverá se direcionar às questões vitais da humanidade toda, se quiser ter um significado para as religiões do Ocidente e do Oriente e para a humanidade".

${ }^{41}$ Para Terry Dohm, colocar as religiões debaixo da categoria do reino de Deus como Moltmann faz soa como também absolutista e sacrifica a identidade das outras religiões. Ver DOHM, Terry. The Key to Dialogue and Peaceful Co-existence. In: KONING, Andrea (Ed.). Glaube und Denken Mission, Dialogue and Peaceful Co-existence: Living Together in a Multireligious and Secular Society: Situation, Initiatives and Prospects for the Future. Frankfurt: Peter Lang, 2010. p. 69-76. A crítica de Dohm se baseia na corrente pluralista que, como já mencionamos, segundo o pensamento de Moltmann, não ajuda em nada no diálogo inter-religioso. Todavia, por ser uma crítica relativamente recente à postura de Moltmann, consideramos interessante fazer menção.

${ }^{42}$ MOLTMANN, 2013, p. 216-217. 
do seu Espírito; qualquer coisa que não pode permanecer em sua presença é anticristã e demoníaca ${ }^{43}$.

\section{Considerações finais}

Ao final desse percurso é possível perceber que as indicações de Moltmann para o diálogo inter-religioso, ainda que pequenas se considerarmos proporcionalmente todos os seus escritos, trazem importantes considerações para os cristãos pensarem um diálogo inter-religioso que saia de uma perspectiva absolutista ou de superioridade frente às outras religiões, principalmente com relação àquelas que não possuem um texto escrito como as indígenas ou algumas religiões africanas.

Mostramos que o diálogo, no pensamento de nosso teólogo, faz parte da missão da própria igreja, que deve se abrir para ele sem, contudo, perder a própria identidade cristã. Assim, é possível perceber porque Moltmann não segue nem por uma via do relativismo religioso, nem pela via de uma teologia do pluralismo religioso. $\mathrm{O}$ diálogo que propõe, seja pela via indireta, seja pela via direta, pressupõe, por sua vez, que aquele e aquela que se propõe a fazê-lo seja alguém que já alcançou uma posição firme em sua própria religião, a fim de poder fazer um diálogo sério com membros de outras religiões.

Dessa forma, essas indicações que podemos extrair do pensamento moltmanniano se mostram como convite ao cristianismo para que este abra mão de toda e qualquer forma de imperialismo na evangelização, sendo ao mesmo tempo um convite para que, como cristãos, assumamos uma postura de humildade, dispostos a aprender e ensinar no diálogo sério e acolhedor com as outras religiões.

\section{Referências}

DECLARAÇÃO Nostra Aetate sobre a igreja e as religiões não-cristãs. Disponível em: $<$ http:// www.vatican.va/archive/hist_councils/ii_vatican_council/documents/vat-ii_decl_19651028_nostra-aetate po.html>. Acesso em: 27 maio 2019.

DOHM, Terry. The Key to Dialogue and Peaceful Co-existence. In: KONING, Andrea (Ed.). Glaube und Denken Mission, Dialogue and Peaceful Co-existence: Living Together in a Multireligious and Secular Society: Situation, Initiatives and Prospects for the Future. Frankfurt: Peter Lang, 2010. p. 69-76.

KÜNG, Hans. Ser Cristão. Rio de Janeiro: Imago, 1974.

MOLTMANN, Jürgen. A Common Earth Religions: World Religions from an Ecological Perspective. Ecumenical Review, Geneva, v. 63, n. 1, p. 16-24, mar. 2011.

. A Response to my Pentecostal Dialogue Partness. Journal of Pentecostal Theology, Cleveland, v. 2, n. 4, p. 59-70, 1994.

Direitos humanos, direitos da humanidade e direitos da natureza. Concilium Brasil, Petrópolis, n. 228, p. 135-152, mar. 1990b.

${ }^{43}$ MOLTMANN, Jürgen. A Response to my Pentecostal Dialogue Partners. Journal of Pentecostal Theology, Cleveland, v. 2, n. 4, 1994, p. 67. 

1998.

. El Espíritu Santo y la teología de la vida. Isidorianum, Sevilla, v. 7, n. 14, p. 359-360,

. Ecumenismo en el servicio al mundo. Selecciones de Teología, Barcelona, v. 12, n. 46, p. 174-177, abr./jun.1973.

. Experiências de reflexão teológica: caminhos e formas da teologia cristã. São Leopoldo: Unisinos, 2004.

Igreja no poder do Espirito. Santo André: Academia Cristã, 2013.

Christianity and the World Religions. In: HICK, John; Hebblethwaite, Brian (Eds.).

Christianity and Other Religions. Philadelphia: Fortress, 1981. p. 191-211.

Situación de la teología al final del siglo XX. Catharginensia, Murcia, v. 15, n. 28, p. 247-250, jul./dic. 1999.

. Is "Pluralistic Theology" Useful for the Dialogue of World Religions? In: D'COSTA, Gavin (Ed.). Christian Uniqueness Reconsidered: the Myth of a Pluralistic Theology of Religions. New York: Orbis, 1990a. p. 149-156. maio 1992.

Fundamentalismo e modernidade. Concilium Brasil, Petrópolis, n. 241, p. 141-148,

OLIVEIRA, Kathlen Luana. Tolerância repressiva. Protestantismo em revista, São Leopoldo, v. 12, p. 1-31, jan./abr. 2007.

WOLFF, Robert Paul; MOORE JR, Barrington; MARCUSE, Herbert. A Critique of Pure Tolerance. Boston: Beacon, 1969. 